\title{
Detecting the Fluctuations in Large Samples Using Wavelet Transform
}

\author{
S. AL Wadi ${ }^{1} \&$ Ghassan Obeidat $^{1}$ \\ ${ }^{1}$ Faculty of Management and Finance, The University of Jordan, Aqaba, Jordan \\ Correspondence: Sadam Alwadi, Faculty of Management and Finance, The University of Jordan, Aqaba, Jordan. \\ E-mail: sadam_alwadi@yahoo.co.uk
}

Received: Nov. 7, $2018 \quad$ Accepted: Nov. 16, $2018 \quad$ Online Published: November 26, 2018

doi:10.5539/mas.v12n12p245 URL: https://doi.org/10.5539/mas.v12n12p245

\begin{abstract}
structure break is a famous features in stock market data that gain consideration from many kind of researchers. Generally, it occurs because of unexpected variations in the strategy of the government. Recently, wavelet method (WT) is more popular in the stock market data analysis since it has significant benefits than the other traditional methods. In this research paper, the discrete wavelet transform (DWT) based on Daubechies model will be used to capture the structure break in Amman stocks market/Jordan (ASE) using dataset from 2010 until 2018.
\end{abstract}

Keywords: stock market data, wavelet transform, structure break

\section{Introduction}

Recently, many kind of researchers have concentrated on detecting the main features in stock market data. On these features is the structure break. this feature is very important since there are observed behaviors that arise in stock market data. Also, the scholars confidence to make deep understanding about the probable development in the future.

(Sarkar, 2003) was highlighted the concept of structure break detections, (Banerjee, \& Urga, 2005) improving and initializing some models to detecting the structure breaks for long memory volatility data. structural break was defined as the performance of the series that might change during a specific period of time before reverting back to its original behavior. There are some assumption in economic reveal that the relationship changes over time some of these sudden changes have been explained using some of tradition models as regression models for more details (Hackl, 2013).

Now, in this research paper we will detect the possible available structural breaks in ASE from the mentioned period of time based on WT specially Daubechies wavelet method since this method is restricted in both time and frequency domains for more details refer to (Alfaouri, \& Daqrouq ,2008; Wang, \& Simoncelli, 2005; Gençay, et. Al., 2001; Daubechies, 1992; Chui, 2016).

This article is organized as: after the introduction then in section 2 the mathematical model will be presented. Then the methodology, results and discussion will be presented in section 3 then finally, the conclusion is in section 4 .

\section{Wavelet Transform}

It is well known that WT is generated from Fourier transform (FT). Therefore, WT and FT will be drawn under the sine and cosine models. WT is a function that focus on time and space and satisfy the following assumption (Anvary, et al., 2012):

$$
C_{\varphi}=\int_{0}^{\infty} \frac{|\varphi(f)|}{f} d f<\infty
$$

$\varphi(f)$ is the FT function.

WT is a very famous model in mathematical theory which has many applications in various fields such as signal processing, finance and engineering. This model was modified to solve some problem which related to FT model specially with the data focus on time-space domain and also non- stationary data. Generally, father and mother wavelet are the most important components in the WT's processes since father WT generate the approximation coefficients (has the important features in the dataset) while mother WT introduce the detailed coefficients. Father and mother WT will be represented in the following equation respectively with $\mathrm{j}=1, \ldots, \mathrm{J}$ in the J-level wavelet 
decomposition: (Ramsey, 1999; Yogo, 2008)

$$
\begin{aligned}
& \phi j, k=2^{-j / 2} \phi\left(t-2^{j} k / 2^{j}\right) \\
& \varphi j, k=2^{-j / 2} \varphi\left(t-2^{j} k / 2^{j}\right)
\end{aligned}
$$

J:maximum scale sustainable by the number of data points. Moreover, father wavelets and mother wavelets should satisfy the following conditions:

$$
\int \phi(t) d t=1 \text { and } \int \varphi(t) d t=0
$$

If $\mathrm{f}(\mathrm{t})$ is a Time series data, then it can be represented by WT using father and mother WT as $\mathrm{k}=\{0,1,2, \ldots\}$ and by $\{S\}=2^{j},\{j=1,2,3, \ldots J\}$ and the transformed data can be generated using the following equation (Ramsey, 1999; Yogo, 2008):

$$
\begin{gathered}
S_{j, k}=\int \phi_{j, k} f(t) d t, d_{j, k}=\int \varphi_{j, k} f(t) d t, \\
F(t)=\sum S j, k \phi j, k(t)+\sum d j, k \varphi j, k(t)+\sum d j-1, k \varphi j-1, k(t)+\ldots+\sum d 1, k \varphi 1, k(t) \\
S j(t)=\sum S j, k \phi j, k(t) \\
D j(t)=\sum d j, k \varphi j, k(t)
\end{gathered}
$$

$S j(t)$ and $D j(t)$ are generating the smooth and details coefficients respectively (Ramsey, 1999; Yogo, 2008).

\section{Methodology, Results and Discussion}

\begin{tabular}{|c|c|c|c|c|c|c|c|}
\hline Mean & 4460 & Maximum & 5633 & Standard dev. & 419.2 & L1 norm & $8.832 \mathrm{e}+06$ \\
\hline Median & 4398 & Minimum & 3839 & Median Abs. Dev. & 294.8 & L2 norm & $1.994 e+05$ \\
\hline Mean & 4108 & Range & 1794 & Mean Abs. Dev. & 345.4 & Max norm & 5633 \\
\hline
\end{tabular}

The methodology of this article can be summarized as:

1. The researchers are giving some description statistics for the dataset used in this paper.

2. The dataset will be decomposed using WT in order to detect the structure change.

3. Finally, the structured breaks will be detected for the data used which are daily from ASE from 2010 to 2018 using about 2000 observations.

Table 1. Statistical analysis using WT

Table 1 shows the basic statistical values needs. Therefore, there are very high variation in the dataset used since the range about 1794 also the standard deviation is 419.2 which means that s very fluctuated then these fluctuated.

Now, the transformed data using Daubechies function will be displayed in Figure 1 which shows the stock market data decomposed. Also the fluctuations and the main features will be shown. From Figure 1 the decomposed data are generated from details d1 until $\mathrm{d} 7$. 


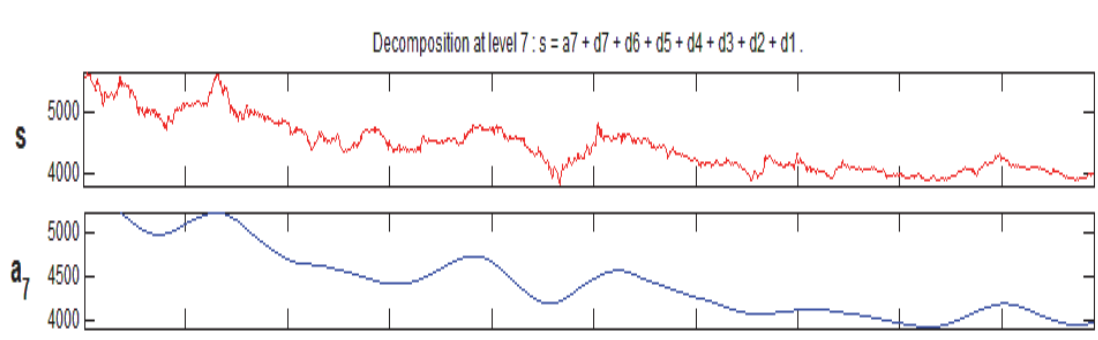

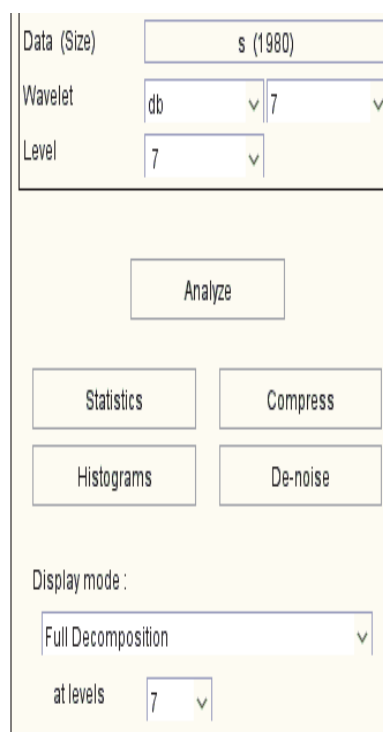

$\square$ show Synthesized Sig.
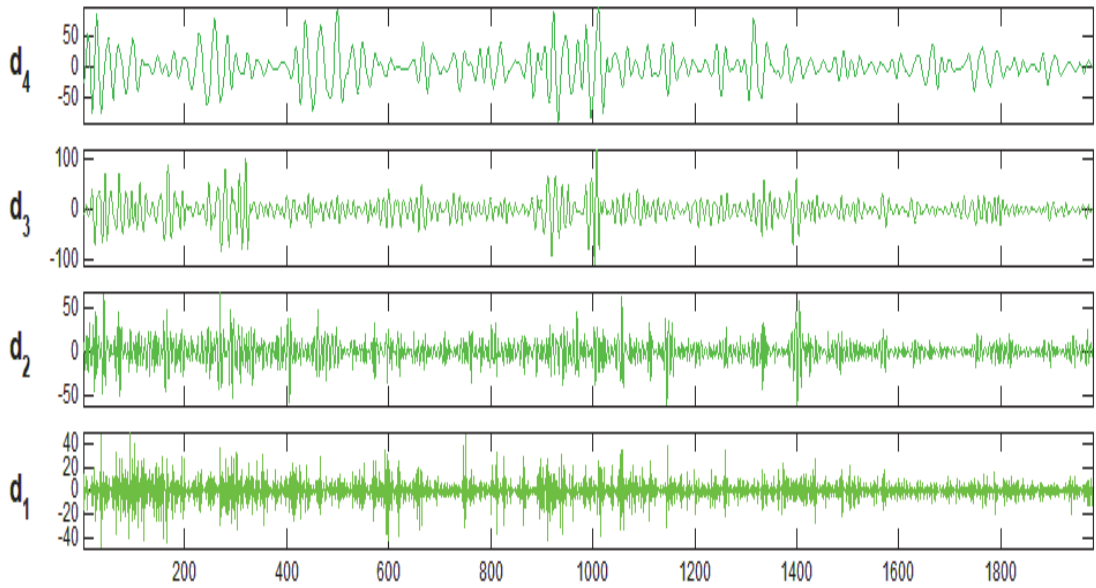

\begin{tabular}{|c|c|c|c|c|c|c|c|c|c|c|}
\hline$x_{+}$ & $Y_{+}$ & $X X Y+_{+}$ & \multirow{2}{*}{$\begin{array}{c}\text { Center } \\
\text { On }\end{array}$} & $X$ & Y & \multirow[b]{2}{*}{ Info } & $x=$ & \multirow[b]{2}{*}{ History } & \begin{tabular}{l|l}
$<$ & $>$
\end{tabular} & \multirow{2}{*}{ View Axes } \\
\hline$x$ & Y. & XY. & & & & & $Y=$ & & $\ll$ & \\
\hline
\end{tabular}

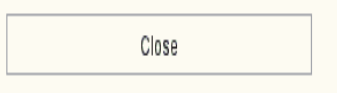

Figure 1. Decomposing Dataset using DWT

From Figure 1 the data set has transformed until d7 so we have 7 details coefficients (these levels are used to detect the main features such as structure break ) and a1 which refers to the approximation coefficients (this level contains the most important features of the data used). Therefore, the time series $\mathrm{X}=\mathrm{a} 1+\mathrm{d} 1+\mathrm{d} 2+\mathrm{d} 3+\mathrm{d} 4+\mathrm{d} 5+\mathrm{d} 6+\mathrm{d} 7$. It would be noticeable $\mathrm{d} 6$ the best details coefficient line for detecting the structural breaks. It is noticeable that the high fluctuations (structural breaks) around the values $5 ; 10 ; 200-220 ; 600-620 ; 1000 ; 1300-1400$. These values represent the years: $2010,2012,2015$. These fluctuations are happened for many reasons such as: Syrian war, some of the policy from Jordanian's government specially after the financial crisis 2009, Commercial facilities for the investments and Tax exemptions and the establishment of new free zones.

\section{Conclusion}

Recently, structural break detections in stock market data have employed a main target for the researchers in the financial time series field. In this paper, we discussed one of the most famous spectral analysis method in order to detect the occurrences of the of structure breaks in Amman stocks market (AES). wavelet transform (WT) is the mathematical model has been used doing this task.

It is well known for the researchers, Fourier transform is traditional model and is unable to detect the fluctuations from Non- stationary data specially stock market data since this model is localized in frequency domain only without any consideration for time domain. The dataset from the year 2010 -2018 has been collected (around 2000 
observations) then the data has been decomposed using WT. Therefore, as a result, the most important featured is detected and DW is a perfect model to capture the structure break events in content of stock market data.

\section{References}

Alfaouri, M., \& Daqrouq, K. (2008). ECG signal denoising by wavelet transform thresholding. American Journal of Applied Sciences, 5(3), 276-281.

Anvary Rostamy, A. A., Ali Aghaei, M., \& Moradzadeh Fard, M. (2012). Forecasting Stock Market Using Wavelet Transforms and Neural Networks: An integrated system based on Fuzzy Genetic algorithm (Case study of price index of Tehran Stock Exchange). International Journal of Finance, Accounting and Economics Studies, 2(3), 83-94.

Azoff, E. M. (1994). Neural network time series forecasting of financial markets. John Wiley \& Sons, Inc..

Banerjee, A., \& Urga, G. (2005). Modeling structural breaks, long memory and stock market volatility: an overview. Journal of Econometrics. https://doi.org/10.1016/j.jeconom.2004.09.001

Chiann, C., \& Morettin, P. A. (1998). A wavelet analysis for time series. Journal of Nonparametric Statistics, 10(1), $1-46$.

Chui, C. K. (2016). An introduction to wavelets. Elsevier.

Daubechies, I. (1992). Ten lectures on wavelets (Vol. 61). Siam.

Gençay, R., Selçuk, F., \& Whitcher, B. J. (2001). An introduction to wavelets and other filtering methods in finance and economics. Elsevier.

Hackl, P. (Ed.). (2013). Statistical analysis and forecasting of economic structural change. Springer Science \& Business Media.

Mallat, S. G. (1989). A theory for multiresolution signal decomposition: the wavelet representation. IEEE Transactions on Pattern Analysis and Machine Intelligence, 11(7), 674-693.

Oraintara, S., Chen, Y. J., \& Nguyen, T. Q. (2002). Integer fast Fourier transform. IEEE Transactions on Signal Processing, 50(3), 607-618.

Ramsey, J. B. (1999). The contribution of wavelets to the analysis of economic and financial data. Philosophical Transactions of the Royal Society of London A: Mathematical, Physical and Engineering Sciences, 357(1760), 2593-2606.

Sarkar, N. (2003). Introductory econometrics for finance. Indian Statistical Institute.

Wang, Z., \& Simoncelli, E. P. (2005, March). Reduced-reference image quality assessment using a wavelet-domain natural image statistic model. In Human Vision and Electronic Imaging X, 5666, 149-160. International Society for Optics and Photonics.

Yogo, M. (2008). Measuring business cycles: A wavelet analysis of economic time series. Economics Letters, 100(2), 208-212.

\section{Copyrights}

Copyright for this article is retained by the author(s), with first publication rights granted to the journal.

This is an open-access article distributed under the terms and conditions of the Creative Commons Attribution license (http://creativecommons.org/licenses/by/4.0/). 